\title{
A Case Study on Sustainable Business of Indian Art and Craft Industry
}

\author{
Sweta R R , and Banumathy Sundararaman ${ }^{1}$ \\ \{17pf38@psgtech.ac.in*, sbm.afd@psgtech.ac.in $\left.{ }^{1}\right\}$ \\ Student", Assistant Professor, Department of Apparel and Fashion Design, PSG College of \\ Technology Coimbatore ${ }^{1}$
}

\begin{abstract}
The Indian Handicrafts are exclusively known for their cultural heritage and exquisitely skilled craftsmanship. In the present market, there are lots of brands that come into existence with the synergy of artisans and have sustainable business growth. In this study, the focus is on understanding sustainable business in the Indian arts and crafts industry through a qualitative case study method. The data collected are through semistructured phone call interviews and Google survey forms. The collected data are categorized and analyzed through Observe, Think, Test, and Revise (OTTR) method. From this research, the various opportunities to enhance the synergy of artisans and entrepreneurs, analyzing market potential, production techniques of the artisans, design interventions in the craft, the 4P's of marketing strategies, the importance of government policies and schemes, and the effect of competition are explored. The unsustainable business in handicrafts was the key problem that paved way for the rise of this research. This paper explores the unsustainable practices in the handicraft sector through literature review and also provides sustainable business opportunities that could help in the growth of the handicraft business.
\end{abstract}

Keywords: Case study, Craft, Design intervention, Market potential.

\section{Introduction}

Handicrafts are products of decoration or utility made using simple tools and by hand through which the essence of artistic and /or traditional values are expressed [1].

The uniqueness and richness of our culture, history, and community expressed through exquisite craftsmanship and a peculiar yet brilliant mix of colors are Indian handicrafts. Indian handicrafts are eco-friendly and labor-intensive products contributing to the small scale and cottage sector industries having the highest capacity of employment creation and foreign exchange (Forex) earnings.

The different types of handicrafts that Indian artisans and craftsmen manufacture are art metalware, wooden art ware, hand-printed textiles, embroidered goods, marble, and soft stone crafts, papier-mache crafts, clay crafts, imitation and fashion jewelry, and artistic leather goods [2].

The thoughtful admission stated in the 1995 United Nations report of the World Commission on Culture and Development

that when the importance of culture is undervalued there is the failure of many development projects [3]. 
The micro small-scale enterprises of handicrafts have to carefully design their social and organizational structure with an in-depth understanding of the cultural trends and rapidly changing environment along with the strength and weaknesses of the craft while planning the business model. A sustainable business growth focuses on four-dimensional (environment,economic, social, and cultural) wellbeing by getting to grips with the challenges and threats [4].

\section{- Artisans/Craftsmen}

The $93 \%$ workforce of the handicraft sector is unorganized and there is a lack of support for acquiring and developing skills [3]. Despite the un organization of this sector, this sector is estimated of employing 6 million artisans/ craftsmen and the large numbers of people in this sector belong to the economically weaker section and are women. The artisans/ craftsmen are generally situated in the rural and semi-urban areas of the country [5].

The rapidly increasing industrialization and urbanization of the country could be one of the factors for the declined growth of handicrafts and a reason for constant competition between handmade and machine-made products. With the increasing developments, people often tend to forget the value of handicrafts and their association with our history and culture. The traders were found to bridge the broken relations of artisans and consumers with the growing industrialization and urbanization [6]. The domestic market for the handicraft sector is destroyed by the inexpensive machine-made artifacts imported [3]. This declined growth in the handicraft sector could also be one of the factors for the $30 \%$ decline in the number of artisans in India who were joining the group of casual labor over the past 3 to 4 decades according to the UN reports [1]. Along with the decline in the handicraft artisans, the craft also becomes endangered because there is no formal documentation on the craft techniques and materials used in many cases of Indian handicrafts as the artisans believed memory to be the only source of the information bank [6].

\section{- The synergy of artisans and entrepreneurs}

In the concept of partnership between the designer / brand / NGO's and artisans /craftsman /weavers there exists 2 models; one is the sustainable development model and the other is the development aid model [7].

The sustainable development model focuses on training the artisans with new skill sets to provide better livelihood opportunities with design interventions. The development aid model is about providing marketplaces for the artisans to market the products designed and manufactured by them without any design interventions [7].

From the above-discussed models, they either lack in preserving the traditional techniques and unique value of the

craft or in bringing design interventions in their products according to the trending customer needs [7].

To bring traditional arts and crafts into the luxury market there requires a cautious balance of design intervention without losing the value and technique of the traditional craft [7].

A breakthrough in the Handicraft sector can take place when a designer and craftsman/artisans work together in developing the vocabulary of the craft and reaching out to new markets. With the growing concept of globalization came a lot of opportunities and threats to creators on the global market. Hence designers become the bridge to connect the traditional craft with the modern world [6]. 


\section{- Marketing handicraft products}

Lack of quality standards and procedures to ensure the product's quality and performance to the customer like colorfastness, the durability of the products is also one of the major issues faced by the customer as well as the handloom/ handicraft producers while buying and selling the products [8]. To create good international marketing opportunities it is important to maintain the quality standards of the products that are competitive to other international sellers [9].

The success of handicraft industries depends on the quality and look of the finished products as well as the marketing strategies. The Handicrafts manufacturers and artisans are not financially aided to market their products so they depend on Channel agents. The channel agents would earn a notable profit from consumers at the cost of the artisans. To protect artisans similar institutions must co-operate to strategize plans and improve the organization [10].

The more general approach for the handloom/ handicraft producers to promote their craft is through fairs and exhibitions but they do not create a strong and long-lasting impact in the mind of the consumers. So it is important to focus on regular and timely promotional and advertising activities to have a strong impact [8]. The market performance of the village handicrafts industry can be improved using quantitative marketing methods with the systematic collection, analysis, and distribution of data [11]. The data could be inclusive of customer feedback, customer preferences, market research, customer surveys, and upcoming changes in the market for the products. But when there is a lack of formal and organized documentation of such data, it could lead to the absence of required products in the market leaving unsatisfied consumers. The long-existing supply chains could create hindrances for the producers to analyze the actual market [8].

The product promotional activities offline were able to focus only on local consumers but when carried on online, a wide range of consumer awareness and flexible market facilities were offered which in turn increased the profit in sales of the product for the artisans [12].

The purchasing decisions of a handicraft product can be mainly influenced by friends and family members. People mainly buy these products because of their appearance and to show their social status [13] but the unavailability of handloom/ handicraft stores in the locality of the consumers restricts the customer's buying decisions [8].

When the price standards are competitive to other countries and the delivery schedules are maintained properly then there are good market opportunities for Indian handicrafts [9].

\section{- Government initiatives towards handicraft sector growth}

The 12th five-year plan of India (2012-2017) for the handicraft sector framed a coherent vision that stated in creating the handicraft sector as a globally competitive sector and also provide the artisans with sustainable employment opportunities by bringing innovation in product design, enhancement in the quality of the product, establishment of modern technologies and safeguarding traditions [2] and also maintain an estimated Compounded Annual Growth Rate of $18 \%$ per annum [3].

During the 18th - 19thcentury India on the trade routes was known exclusively for the craftsmanship of the product (crafts) to the other countries [1]. The demand for Indian handicrafts increased again in the global markets during 2009- 2011 and now it contributes $1.2 \%$ and $1.5 \%$ in the world's market for handicrafts and the country's overall exports. The major export destinations for Indian handicrafts are the USA and UK together which account for 50\% of total global exports and other destinations are United Arab Emirates, Germany, 
and France [2]. The Indian handicrafts exported in the year 2019 value over 128 billion rupees which shows a $7.8 \%$ increase in value in the exports from the previous year (2018).

\section{SWOT analysis of the sector}

The Strength, weakness, threats and opportunity are discussed below.

Strength of the sector

- Unique and skilled craftsmanship.

- Utilization of domestic resources.

- The availability of ample and inexpensive labor.

- Low capital investments are involved in the production of goods.

- Eco friendly sector.

Weakness of the sector

- Decentralization of the sector.

- Inadequate finance.

- Lack of infrastructure.

- Unavailability of raw materials.

- Lack of knowledge on modern technological skills, irregular production and low quality of goods.

- Lack of creative and innovative products.

- Deficient marketing and entrepreneurial skills.

- Lack of knowledge in branding, supply chain management and negotiation.

- Lack of implementation of government policies and schemes.

- Inadequate information on the upcoming trends, target customers and opportunities.

- Restricted credit access.

- Lack of presence in social media and inline stores.

- Lack of involvement in commercialization of the craft.

- An insufficient number of skilled labors.

- Absence of documentation of the craft.

- Absence of documentation of expenses involved in making of the product.

Opportunities of the sector

- The increased recognition from the international consumers.

- The increased demands from national and international markets.

- Government initiatives to protect the craft and support the artisans.

- Rising tourist visits pave the market space for the sale of traditional products.

- E-commerce and social commerce are the emerging platform for artisans/weavers/ craftsmen to market and sell their products directly to the customers.

- Good design intervention without changing the traditional techniques of the craft. Threats of the sector

- Global competitions from other handicraft craft producing countries.

- Low quality of the raw materials used.

- The difference in the pricing of the product from the global competitors.

- Lack of quality standards to access the quality of the product.

- Better quality products by competing country.

- High freight cost in the transportation of goods.

- Lack of support from institutions.

- The extinction of the crafts due to globalized trade. 
- $\quad$ Risk of losing the original identity and traditional techniques of the craft or art forms to manufacture global products.

- Competition between handmade and machine made products.

- Poverty crises could result in the changing occupation of the artisans/ craftsmen to a more sustainable livelihood with higher income.

- Reduced domestic markets due to the intervention of imported cheap machine-made goods.

- $\quad$ Lack of markets to sell the product.

- Inadequate transportation.

- Environmental pollution could result in the degradation of the valuable raw materials used in the crafts.

\section{Case study}

Under the research of social sciences and management, a case study has been an important form of research [14].

Case studies can be used in various forms of research such as descriptive, exploratory, and explanatory [14].

The key feature of the case study method defines it as a factual inquiry that investigates the current events with real-life circumstances, when the borderline between the current events and circumstances are not clearly understood and which consists of evidence of multiple sources [14].

The method of case study is a diligent methodology that is used to study a topic that has an inadequate existing theory

and when the data collection can be from multiple sources in turn allowing the researcher to gain more knowledge and understanding on the topic of research and help in the decisionmaking process and study the cause and effect relationship [14].

Case study methodology of research can be applied when the factors and relationships included are of the large variety that can be observed directly and there is an absence of basic laws to determine which could be important [15].

According to [16] the below are the steps involved in an undertaking case study:

Choosing an appropriate design of case study which could be exploratory and /or explanatory or descriptive.

Determining the area of analysis.

Selecting the cases/samples (which could be either single or multiple) and explaining the reason for the selection of the cases.

Data collection (quantitative and/or qualitative) from multiple sources could strengthen the case study if they are transparent.

Manipulation of collected data (data reduction, data display, data categorization, data contextualization).

Systematic analysis of data (qualitative data analysis techniques: explanation building, pattern matching, with-in case analysis, and cross-case analysis) and a clear explanation of the findings retrieved from the data will give a distinctive feature of a high-quality case study.

Presenting the observed evidence and result of the study.

Establish reliability and validity in the findings of the research (through four main criteria: construct validity, internal validity, external validity, and reliability). 


\section{- Interview format of data collection}

One of the most familiar methods for collecting qualitative data is the interview. The concept of the qualitative interview is to gain knowledge based on the real-life experiences of the interviewees The purpose of interviews can be of two types: 1 . it is used to test the hypothesis framed through more structured questions and standardized analysis, 2 . it is used to explore deeper and understand better, the area of research and different perceptions to generate hypotheses [17].

The interview format is classified broadly as unstructured, semi-structured, and structured. Unstructured and semi-structured interviews provide qualitative data and structured interviews provide quantitative data [17]. Unstructured in- interviews are used when the interviewer has very limited knowledge on the subject of analysis and could be used to gain insights but they are not a source of reliable data. Semi-structured interviews provide details, deeper insights and different perceptions of the insiders on a particular area of analysis paves way for hypothesis testing and quantitative analysis from the interviewee's responses. The structured interviews are conducted when the interviewer has more knowledge on the particular area of analysis and poses specific questions which require specific answers [18].

\section{- $\quad$ Semi-structured interview}

Semi-structured interviews are planned for the time and location of the interview to take place. The semi-structured interviews are framed with open-ended questions which are later carried forward through the emerging topics from the conversation between the interviewee and interviewer. The interview lasts a minimum of 30 minutes and a maximum of several hours. These interviews can be conducted individually or in groups. When the interview is conducted individually the interviewer and interviewee can ask and share personal and professional details but when conducted in groups the interviewer can gain knowledge and different perceptions on the professional area of analysis and could not gain personal information [17].

Types of semi-structured interview questions [18].

Grand tour questions are a type of questions about which the interviewee is well experienced/ well known. In this type of question, there is a chance for the interview drifting away from the subject of analysis so these types of questions could be accompanied with more specific parameters and are regarded as specific grand tour questions. When the interviewer accompanies the interviewee while performing his job at his workplace, for a tour it is known as a guided grand tour. When the interviewer wants to understand and analyze more on a task of the interviewee, he/she may be asked to perform it and these are known as task-related grand tours.

Example questions might be similar to grand tour questions but they are more specific and ask for an example related to a single event to the interviewee.

Native language questions would ask the interviewee to respond in their own words. It could be direct language questions that would ask the interviewee directly on how they refer to certain experiences or hypothetical interaction questions which would ask the interviewee how they respond to a given situation along with the people involved.

Prompts are important in semi-structured interviews just as the questions to keep the flow of the interview and to relieve when the responses of the interviewee turn to mush. The informal prompts are unscripted that are nothing but the reassuring interjections and sounds given by the interviewer to assure the interviewee that they are listening and are curious to know more about it. The formal prompts are planned probes that are scripted at the end of a formal question if the interviewee forgets to mention it. 
Structural questions would ask the interviewee to logically structure the world this could help them list all variables and their relationship with one another.

There may be certain situations in which the interviewee may get carried away from the topic, it is better to give them time to complete the talk and gently bring them back to the topic of analysis rather than cutting in the middle and trying to control the interview, in which we may miss out some important points.

Selection of interviewees in a semi-structured interview

The interviewees selected should belong to a homogeneous group and the critical similarities shared are related to the area of analysis. This sample of interviewees could be selected through purposeful sampling to maximize the richness of data and for gaining indepth knowledge and setter perceptions [17].

Technical issues in a semi-structured interview:

The interviews conducted are usually recorded in an audio/ videotape recorder and/or note-taking method. For recording the interview using the audio/ videotape recorder the interviewer should get the consent of the interviewee before the interview. The recorded data should be kept confidential and destroyed after the completion of the analysis. The quality of the recorded video or audio could be an issue with background noises, recorder placement, and others [17].

Transcription of recorded data into text could be complicated because if the transcribers misplace a comma or a quotation mark or misunderstand phrases or meaning it could change the meaning of whole sentences. At times the transcribers would have to make judgment calls for ensuring the accuracy of interpretation. The expert transcribers would read the written transcripts while listening to the recorded audio for accurate interpretation [17].

Data management and analysis processes using software programs like Atlas ti, Folio Views, and NVivo could be time-saving, systematic [21], used for transcribing recorded data using codes, organizing a large volume of data, and managing the analysis process by categorizing topics and establishing links between variables [16].

Ethical issues in a semi-structured interview:

During the interview the interviewee might delve into their personal grieve experiences and divert from the area of analysis, to resolve this interviewer should be able to provide them psychological support to undo the stress and provide comfort. Confidentiality and anonymity of the information shared and the interviewee should be maintained based on the information shared. Verbal consent for participating in the interview from the interviewee after clearly explaining the area of analysis and in-depth information required. It should also provide the participants to reconsider their decision. The interviewee must not be exploited by the interviewer for personal gains [17].

\section{- Data analysis of a semi-structured interview}

The central method of data analysis in a case study is the OTTR method concluded with an explanation. The researcher records the observations and goes through the observations and thinks about them for further proceedings and alternate explanations. These observations are tested and revised if requires and then it is tested again till the researcher gains correct results. If the researcher does not want to revise the observations the data could be concluded with an appropriate explanation [19].

The main objective of this study is to understand the sustainable livelihood opportunities adopted by Indian art and craft ventures an do understand the 4P's of marketing of Indian art and craft ventures through qualitative semi structured interviews and survey forms. 


\section{Methodology}

\section{- $\quad$ Problem identification}

From the literature review undertaken the sector of the Indian handicrafts industry is a wide unorganized sector and each art and craft is bound to its own set of strengths, weaknesses, opportunities, and threats. But the increasing livelihood problems faced by the artisans/ craftsmen and the inefficient marketing techniques and market analyses were considered to be the major problem of this sector. So the main objectives were framed to focus on these problems and to derive solutions. To approach this study scientifically, the variables were taken from the literature. 23 variables were considered in this research which could address the objectives framed.

\section{- $\quad$ Sources of data collection}

The secondary sources of data collected were from the research articles and websites for literature review by which the major problem faced by the Indian handicrafts industry was identified and the variables required for the preparation of the questionnaire for collection of data from primary sources were obtained.

The primary source of data collection is done through semi-structured interviews via phone calls and Google survey forms. The variance in the techniques of primary data collection is based on the availability and the convenience of the samples.

- $\quad$ Sample selection

The target samples of the research are entrepreneurs or individuals who are both artisan and entrepreneur who are running a sustainable business in the Indian art and craft industry.

The convenient sampling was adopted for selecting the samples through social media (Instagram) and references. The selected samples phone calls, Whatsapp messages, Instagram DM's, and emails.

\section{- Questionnaire farmed for the data collection}

The questionnaire was designed based on the variables obtained from the literature review. The variables are Design interventions in the craft, Information on up-coming trends, Market awareness, Infrastructure, Government Policy and schemes, Technology and tools, Transportation to port, Cost of credit, Income tax, High excise, Access to raw materials, Shipping and air freight problems, Duty drawback, Marketing efficiency, Presence in buyer's market, Cost of raw materials, Distribution channels, Wages of artisans, Skill training to artisans, Product development strategies, Global competitions, Cost of the product and Lead time for processing orders.

In the preparation of the questions from these variables the questionnaire is categorized in phases and prepared.

The phase consisted of questions for details on the name of the samples, their profession whether an artisan- entrepreneur or entrepreneur, the name of his brand, and his journey with the brand.

- $\quad$ The synergy of artisan and entrepreneur phase

This phase consisted of questions to know the details on where the artisans of the brand are located, the type of artisans they are associated with, the sustainable livelihood of the 
artisans, the creating the bond of trust with the artisans, and the infrastructure of the artisan's workspace.

\section{- Analyzing market potential and product development phase}

In this phase, the method using which the samples analyze the market potential for their product, the design interventions introduced, the product development techniques, raw material procurement, lead time management, quality control, packaging of products, technological benefits, and logistics management were discussed.

\section{- Marketing phase}

The 4P's of marketing promotion, place of distribution, pricing of the products, and products they design.

\section{- $\quad$ The phase of opportunities and threats}

The importance of government policies and schemes in their business, the effect of income taxes, duty drawback, credits, and high excess duty, and the global and industrial competition faced by them were discussed.

\section{- $\quad$ Tentative interview}

A tentative interview was conducted to analyze the efficiency of the questionnaire, to analyze technical issues, and to gain feedback from the sample on how the interview was conducted. Through convenient sampling, an entrepreneur named Ms. Khatija who owns a brand named "Pink flower" selling organic and sustainable products was approached.

\section{- $\quad$ The collected data}

The data collected were through semi-structured interviews via phone calls and Google survey forms. The data from survey forms were collected by mailing and messaging Google survey form links to the samples and the responses were converted into detailed transcripts. The data from the semi-structured interview via phone calls were recorded using the Automatic Call Recorder Latest (ACR) mobile app. The recorded data are converted into transcripts. The recordings are deleted after the data are converted into transcripts. The transcripts are written in the questionnaire order which would further help in data categorization and data analysis. Six samples took part in the research.

Ms. Sachii is an entrepreneur who was identified via social media and approached through email. She participated in research through Google survey forms and her response was recorded in Google survey forms and converted into detailed transcripts.

Mr. Sujit is an artisan-entrepreneur who was identified through word of reference and approached through Whatsapp. He participated in the research through Google survey forms and his response was recorded in Google survey forms and converted into detailed transcripts.

Mr. Lakshmi Narayanan is an artisan- entrepreneur who was identified through word of reference and approached through phone calls. He participated in the research through semistructured interviews via phone calls with audio recordings and converted them into detailed transcripts.

Mr. Shanmugam is an artisan- entrepreneur who was identified through word of reference and approached through phone calls. He participated in the research through semi-structured interviews via phone calls with audio recordings and converted them into detailed transcripts. 
Ms.Tanmana is an entrepreneur who was identified via social media and approached through Instagram DM's. She participated in the research through semi-structured interviews via phone calls with audio recordings and converted them into detailed transcripts.

Mr. Gowtham is an artisan- entrepreneur who was identified through word of reference and approached through Whatsapp. He participated in the research through semi-structured interviews via phone calls with audio recording and converted it into a detailed transcript.

\section{Data analysis}

The collected data are analyzed manually through the concept of observing, thinking, test and revising (OTTR) concluded with an explanation. The collected data are categorized, observed, and concluded with an explanation. The categorization of the data was done by arranging the data concerning that of the variables and key points for the easy analyses of the collected data. This categorized data was observed for the number of similar opinions and variations within a variable and for analyzing the importance among different variables through think and test. The analyzed data is concluded with an explanation.

\section{Results And Discussion}

\section{- Problem identification}

The unsustainable business of artisans/ craftsmen in the Indian handicraft industry and the inefficient marketing techniques followed by them were identified as the problems.

\section{- $\quad$ Sources of data collection}

The secondary sources of data collected were from the 23 research articles and websites for literature review.

The primary source of data collection was done through semi-structured interviews and Google survey forms. About 33.3\% of samples responded through Google forms and 66.7\% of samples replied through semi-structured interviews via phone calls.

The data collected from the literature review gave a clear description of the industry and the requirements for improving the industry. It enhanced the efficiency of the questionnaire for the primary collection of data. Based on the convenience factor of the samples the data collection from primary sources was based on Google survey forms and semi-structured interviews via phone calls.

\section{- Sample selection}

The total number of target samples approached was 32 the samples who agreed to be part of it were 6 and the response rate is $18.75 \%$.

Of the samples who responded to the interview, $66.7 \%$ were artist-entrepreneurs and $33.3 \%$ were entrepreneurs.

Through convenient sampling, the samples who responded $33.3 \%$ were selected through social media (Instagram), and $66.7 \%$ were selected through reference.

Among the selected samples, $33.3 \%$ were approached through phone calls, $33.3 \%$ were approached through Whatsapp messages, $16.7 \%$ were approached through Instagram DM's, and $16.7 \%$ were approached through emails. 
The response rate was less due to the busy schedules of the entrepreneurs due to the Diwali season and the inconvenience of the target samples to share their business opportunities.

The questionnaire is arranged in chronological order such as introduction to the designer and the brand, synergy of artisan and entrepreneur, analyzing market potential and product development, 4P's of marketing, and the opportunities and threats to the brand. The variables discussed were accommodated under appropriate phases. It is done to support the flow of conversation with the samples and for easy categorization.

\section{- $\quad$ Tentative interview}

The tentative interview was conducted with Ms. Khatija an entrepreneur who owns "Pink flower" a brand that sells organic and sustainable products via online meetings. The efficiency of the questionnaire was good and the feedback received from the sample was also good. She felt great sharing her experience. But the conduct of the interview did face a lot of technical issues like recording the data live as videotape, voice breakage, and the network.

So the rest of the meeting was scheduled using telephone calls as there won't be any network issues as such in an online meeting. The recording of phone calls was done using the Automatic Call Recorder (ACP) mobile app. To avoid further disturbances based on the network issues and also keep the convenience of the samples in mind the Google survey forms were created with the same questions.

\section{The data collection}

- Ms. Sachii: The name of the first subject is Ms. Sachii. She is an entrepreneur who owns the brand "Terracotta by Sachii" which was launched in September 2020. This brand was launched in an attempt to bridge the gap between heritage pottery artisans and discerning buyers.

The skilled artisans for her brand are located in Delhi, Rajasthan, Gujarat, Uttar Pradesh, and many other states. She ensures sustainable employment to her artisans by buying upfront and not withholding their money or inventory. She works closely with the artisans and genuinely tries to create value for them. According to Ms. Sachii, the working area of the artisans are manageable. And no changes have been brought to the infrastructure by the entrepreneur.

The market potential for her products is analyzed through existing data, market surveys, and customer feedback, and customer preferences. She did bring design interventions in her product by introducing a few new products as per current market trends while giving the artisans the freedom to execute their skills and sensibilities. The raw materials for making the products are made by themselves and during the situations when the raw materials are purchased from the market they are transported using courier services and she does not face any issues with the transportation. The artisans with whom she is working are national and state awardees so she trusts their quality and workmanship. The products produced are of traditional techniques and the tools used are a combination of traditional and modern. The lead time is maintained by starting well in advance. She considers technology as a boon as it gives the benefit of selling online during pandemic times. The quality assurance of her products is one the most and it is well-taking care of but at the same time, she notes that the small imperfections the beauty of the handcrafted products. The packaging of the products is kept 
sustainable since clayware is bulky and heavy, it is well protected and cushioned to avoid any damages using a good quality of 5 plies and above corrugated boxes, a lot of old newspapers, and jute bags. According to her, her customers give importance to packaging as well. The finished products are delivered to the customers through courier services.

She sells her product online and on social media. The promotional activities are done through social media and online. The product categories include accessories, home décor, art, and collectibles. The pricing range is between Rs. 500- Rs. 5000.

She feels government policies and schemes play a very important role in her business and didn't have any issues with high excise duty, income taxes, credits, and duty drawbacks. She also faces only moderate global competition and with that of machine-made products.

- Mr. Sujit: The name of the second subject is Mr. Sujit. M. P. He is an artisan and entrepreneur who own the brand "Bhavm" which was launched in 2006. This brand was launched in an attempt to empower traditional art along with craft skills.

The artisans for his brand are located at Kalpetta, Wayanad district in Kerala. He works with skilled, semi-skilled and also provides training to general laborers and work with them. By introducing traditional art in lifestyle products they assure a sustainable market through which they assure sustainable livelihood opportunities. He is an artisan so he feels

The market potential for his products is analyzed through customer feedback and customer preferences. He did bring design interventions to his products by adding traditional paintings to them. The raw materials for making the products are made by themselves and purchased from the market. The raw materials are transported via road to the workshop and the cost of transportation is an issue faced by them. Through years of experience in this craft, he has developed the ability to analyze raw materials. The products are made using traditional and modern techniques and the tools used are a combination of traditional and modern. The maintenance of lead time is a very difficult issue faced by them. The benefits of technology in his business are online marketing and payments. The quality of the finished products is also analyzed by his years of experience. The packaging of the products differs according to the characteristics of the products. According to him, his customers give importance to packaging as well. The finished products are delivered to the customers through courier services, road, ship, train, and air. The difficulties faced by him in delivering his products are damage of products and delivery delay.

He sells his products online, on social media, in stores, exhibitions, and middlemen. The promotional activities are done through social media. The product categories include textiles, apparel, accessories, home décor, jewelry, art, and collectibles. The pricing range is between Rs. 500- Rs. 5000. He feels government policies and schemes play a very important role in his business and does find high excise duty and credits difficult. He faces only moderate global competition but with that of machine-made products, he faces very high competition.

- Mr. Lakshmi Narayanan: The third subject is Mr. Lakshmi Narayanan. He is an artisan and entrepreneur who own the brand "Karuppur Kalamkari" which is a traditional art that is being passed on from generation to generation.

The artisans for his brand are located at Sikalnayakanpet, Tanjavur district nearly 25 kilometers away from Kumbakonam. He works with skilled, semi-skilled, and also provides training to general laborers and works with them. By introducing Kalamkari in lifestyle products other than temple orders they are sure of market potential for the art through which they assure sustainable livelihood opportunities. All essential facilities are well provided in the working area. And no changes have been brought to the infrastructure of the working area.

The market potential for his products is analyzed through customer preferences and customized orders. He did bring design interventions by using Kalamkari paintings on 
different product categories. The raw materials for making the products are made by themselves and fabric is purchased from the market in the areas like Tirupur, Erode, and Anglo-French Textiles (Pondicherry). The raw materials are transported through courier services to the working area and they do not face any issue in transportation. Through years of experience in this craft, they have developed the ability to analyze the fabric materials whether they are suitable for the painting are not. The products are made using traditional techniques and the tools used are traditional. There is no issue in lead time maintenance because all their buyers are aware of the time taken in producing the product except new customers. He said that for sarees it takes 15 days for production and if there are any new designs then they will ask for advanced time and during rainy seasons the buyers themselves provide extra 15 days. The benefit of technology in his business is social media marketing and improves the ease of communication with the customers in sending pictures of finished products. The quality of the finished products is also analyzed based on the finishing of the painting and he said that they have done a $100 \%$ perfect finish. The packaging of the products differs based on international or national customers. But they have ensured a secured packaging and take the responsibility of the products until it reaches the customers. According to him, his customers give importance to packaging as well. The finished products are delivered to the customers through courier services. There are no difficulties faced by him in delivering his products except time delay but they try to manage it in production.

He sells his products online, social media, showrooms related to handicrafts, government and non-government exhibitions, buyers and they also sell directly to the customers. The promotional activities are done through social media, online, museums, handicraft events. The product categories include textiles, apparel, accessories, home décor, art, and collectibles. The pricing is completely based on the design and the fabric they use between Rs. 30- Rs. 15000 .

He feels government policies and schemes play a very important role in his business and feels it has only benefitted their business. He does not find any issues with high excise duty, income tax, duty drawback, and credits. He also does not face global competition even in exhibitions they exhibit their tools and products and explain their craftsmanship to their customers which always gains them a higher value than the global competitors. He said that they don't feel the competition with the machine-made products because the customers associated with them know the value of hand-painted kalamkari.

- Mr. Shanmugam: The name of the fourth subject is Mr. Shanmugam. He is an artisan and entrepreneur. His journey in the bamboo handicraft started because of his childhood interest. He got his training in Assam with the help of government support.

The artisans for his brand are located at Village called Nattamangalam approximately 7.7 kilometers away from Salem, Tamil Nadu. He provides training to general laborers and works with them. With time they evolved from making crafts to other product categories which provided sustainable livelihood opportunities. The working area is owned by him and is well equipped with machinery.

The market potential for his products is analyzed through customer feedback and customer preferences. He did bring design interventions to his products by expanding his product categories into interior décor products and constructions. The raw materials for making the products are purchased from the market. The raw materials are transported via road to the

workshop and the cost of transportation is an issue faced by them. The quality of the raw material is analyzed through standard procedures. The products are made using traditional and modern techniques and the tools used are a combination of traditional and modern. The lead time maintenance is not an issue faced by them. He feels that technology has benefitted his 
business online marketing. The quality of the finished products is also analyzed and if there is any problem faced by the customers they ensure the service after the purchase. The packaging of the products differs according to the characteristics of the products and most of the products like interior décor products will require them to go to the customer's place and place the fixtures. According to him, his customers give importance to packaging as well. The finished products are delivered to the customers through courier services, road, ship, train, and air. The difficulties faced by him in delivering his products are damage of products and delivery delay.

He sells his products online, on social media, in stores, exhibitions, and middlemen. The promotional activities are done through social media, word of mouth, and exhibitions. The product categories include home décor, art, and collectibles; they are also planning to join construction. The pricing range differs from product to product.

He feels government policies and schemes play a very important role in his business and do not face any difficulties with high excise duty, income tax, duty drawbacks, and credit facilities. He faces only moderate global competition and with that of machine-made products; he feels the uniqueness of his products (USP) is what adds value to his business.

- Mrs. Tanmana: The fifth subject is Mrs. Tanmana who is an entrepreneur. She owns Apaapi Studio. When the entrepreneur found the market potential for the northeastern handloom fabrics in the market her journey towards Apaapi began.

The skilled weavers for her brand are located in Assam. She ensures sustainable employment to her weavers through advance payments. She works closely with the weavers and explains that communication could be a key point; receiving proper payments and giving that boost of encouragement that their products are selling well in the market had led to the synergy of her weavers with her. According to her, there are issues with the infrastructure. And the entrepreneur has taken steps in providing knowledge to the weavers to improve the infrastructure.

The market potential for her products is analyzed through market research. She did bring design interventions in her product by experimenting with the already existing motifs and trying to mix and match them, with the colors and with the warp and weft yarns. The raw materials for making the sarees are purchased from the cotton yarn manufacturers and are transported by train. The biggest issue she faced in the transportation of raw materials is the delivery of other raw materials to that of the ordered ones, so a lot of follow-ups are required from the entrepreneur's side and time delay. The quality of the products is checked through industry experts. The products produced are of traditional techniques and tools used are a combination of traditional but with the help of government loans they are few who can buy modern handlooms. The lead time is maintained by planning and starting well in advance. Since she owns an online clothing brand she feels technology at one point is very helpful in promoting the brand and also in cost-effectively selling the products but on the other side it also does increase the competition in the market and the absence of a physical appearance of customers is still at disadvantage. The quality assurance of her finished products is also checked by industry experts. The packaging of the products is kept sustainable and minimalistic and does send customized messages to her customers along with the products. According to her, her customers give importance to packaging as well. The finished products are delivered to the customers through courier services. She finds it comfortable and didn't face any delivery issues.

She sells her product online, on social media, and also through exhibitions. The promotional activities are done through word of mouth, social media, and exhibitions, and online, and the importance is given to content in social media marketing. The product categories include sarees and home textiles. The pricing range differs majorly because of the 
raw material procurement charges, logistics charges, weaving cost, and after adding profit margins the finalized cost is estimated; it could vary but they try to ensure sustainable pricing so all people could buy their products.

She feels government policies and schemes play a very important role in her business through skill training programs and provide knowledge and didn't have any issues with high excise duty, income taxes, credits, and duty drawbacks. She also faces global competition but a little less which motivates her to be fast and creative with designs, as well as marketing but the USP of the product, would add value to it in the marketplace. There is competition for handloom products with that of power loom products in pricing level, time, and mass production.

- Mr. Gowtham: The name of the sixth subject is Mr. Gowtham. He is an artist and entrepreneur. His journey in arts started because of his passion and later developed as a full profession.

He is a skilled artist who also trains his students. He is a multi-professional as he works as a teacher, modern artist, and commercial artist. He balances his professions through planned schedules. He has a home studio where he paints and handles classes for students. According to him, it is calm and a comfortable place.

The market potential for his paintings is through customer preferences for commercialized orders and orders from art buyers. Though he works on commercial paintings his compositions consist of modern art with geometric perceptions. The raw materials for making the products are purchased from the market. The raw materials are transported via road to the studio and sometimes when it is ordered from other places it is transported through courier services. During transportation when the paint lids open and leak, the paints could be reclaimed from the stores this is because of the relationship he formed with the shop owners and there were no big issues. Since he buys from standardized brands he is assured of the quality of the raw materials. The products are made using modern techniques and tools (brushes, knives, and rollers). The maintenance of lead time is not a big issue because he would inform his customers before the time required. The timing for his commercialized orders differs due to the medium used and self-availability. He said he would not schedule time for his compositions and would do with the flow when he wants to do it. But during the times of exhibitions, there is little requirement to work faster and complete in time and at that time he would stick to the lead time. The benefits of technology in his business are promotion; faster exposure and saving time in finalizing paintings to exhibitions. The final finish of the painting is analyzed for the commercial painting to check whether it meets the expectations of the customer but it is not checked in personal compositions. The packaging of the products for commercial orders is packed using a safety pouch so the painting is not affected by water and when personal works are sent to exhibitions they mostly avoid glasswork and use canvas and ensure safe packaging. He does give importance to packaging as well. The finished products are delivered to the customers through courier services because it is easy to track or either is delivered by him. The difficulties faced by him in delivering his paintings are damage to glasswork.

He sells his products through customized orders, galleries, online, social media, exhibitions, and art buyers. The promotional activities are done through social media, exhibitions, and word-of-mouth references. The product categories include art and collectibles.

He feels government policies and schemes play a very important role in his profession. He did not have any issues with income taxes, credit facilities; high excise duty, and duty 
drawbacks. According to him, there is high global competition but it is necessary as it motivates the artist to be more creative and to be updated, and to be active in this field.

\section{Data Analysis}

The given data with the help of a questionnaire was divided into five phases which helped in initial categorization. They are the introductory phase, the synergy of artisan and entrepreneur phase, analyzing market potential and product development phase, 4P's of marketing phase, and the opportunities and threats phase. The further categorization was done with the help of the variables namely Design interventions in the craft, Information on upcoming trends, Market awareness, Infrastructure, Government Policy and schemes, Technology and tools, Transportation to port, Cost of credit, Income tax, High excise, Access to raw materials, Shipping and air freight problems, Duty drawback, Marketing efficiency, Presence in buyer's market, Cost of raw materials, Distribution channels, Wages of artisans, Skill training to artisan, Product development strategies, Global competitions, Cost of the product and Lead time for processing orders.

From the transcripts of collected and categorized data, the data were analyzed using the OTTR method. The categorized collected data were observed and tested with the help of further review of the literature. the importance was to variables such as sustainable livelihood of the artisans, the synergy of the artisans and entrepreneur, design interventions, product development techniques, analyzing market potential

4 P's of marketing, importance of government schemes and policies, global and industrial competition.

- $\quad$ The synergy of the artisan and entrepreneur

The synergy of artisans and entrepreneurs has maintained communication which motivates them and provides knowledge and creates value for the artisans by providing sustainable livelihood opportunities and selling their products and helping them earn money. The sustainable livelihood of the artisans is achieved by increasing the product categories (50 $\%)$, buying upfront (16.6\%), and payments in advance (16.6\%).

The major problem faced by the artisans is unsustainable livelihoods which caused problems such as a change in occupation and also low income of artisans and slowly leading to the extinction of the crafts. The interface of middlemen caused exploitation of the artisans so an entrepreneur who is directly associating with the artisans finds it difficult to gain the trust of the artisans. So these factors were considered to be important for the synergy of artisans and entrepreneurs.

\section{- Analyzing market potential}

The market potential was analyzed through customer preferences $(66 \%)$, customer feedback (66\%), market research (33\%), and existing data (16.6\%).

The major problem of the artisans was not analyzing the market potential which is very important for their products for a sustainable livelihood. So this variable was considered important and the various methods of how the entrepreneurs analyze the market were listed.

\section{- Design intervention and product development}


Design interventions opted by the samples are increasing the product categories $(66 \%)$, bringing changes according to trends (16.6\%), and experimentation (16.6\%). The product development techniques opted for are traditional (50\%), modern (16.6\%), and both (33\%).

The design intervention for the handicraft sector is very important mainly it creates sustainable livelihood opportunities but with design interventions also comes a threat to the craft of losing its originality in production technique. But with increasing production orders and for the ease of production there are some changes required in the production technique with modern equipment.

The 4P's of marketing: Among the various place of distribution Stores was preferred by $(66 \%)$ of respondents, Buyers $(66 \%)$, Online $(100 \%)$, social media $(100 \%)$ and Exhibitions $(83 \%)$

One of the important factors for sustainable livelihood is the selling of the product to the customers. The decrease in sales is in direct proposition with a decrease in income which leads them to the change in occupation for a better sustainable livelihood. Involving in physical stores could mean increase is not always feasible with less income so social media and online could have opted as the place of distribution of the products.

Under the various kinds of promotion

- social media was preferred by $(100 \%)$ of the respondents, online $(50 \%)$

, Exhibitions (66\%), Museums (33\%), Word of mouth (66\%)

For any business, the most important tool of communication to its end consumers would be promotion. Hence promoting the craft is also important to gain consumer awareness of the product in the market, to sustain in the market with the craft, and to gain consumers for a sustainable livelihood. Social media and word of mouth is the highly adopted method for promotion.

Pricing

Pricing differs according to the product categories

The important factor of handicrafts is the pricing of the product and its variation. The pricing differs mainly because of the style of the products, raw material cost, production technique, production time, packaging, and logistics cost. So it can differ from product to product.

Among the product categories-Accessories was a part of the product line for $(50 \%)$ of the respondents,

Home décor (66\%), Art and collectibles (83\%), Jewelry (16.6\%), Apparel and textiles $(50 \%)$

For a handicraft producer at present unsustainable livelihood is the major problem because of changing trends so to solve this issue it is important to diversify the product range to avail market for their craft with changing trends.

The 4P's of marketing are discussed to give the artisans the importance of marketing in the handicraft sector and the available opportunities that are adopted to gain customers and for sustainable livelihoods.

- Importance of government policies and schemes

The samples are very well benefitted through the government policies and schemes through the training programs, loan facilities, handicraft, and handloom events and exhibitions. 
The government has issued a lot of policies and schemes for the welfare of the handicraft and handloom sector of India. Many artisans had not properly utilized the resources provided by the government but proper utilization of the policies and schemes could lead to the betterment for the artisan.

\section{- Effect of competition}

The competition for handicrafts always does exist in the market with global handicrafts products and industrial products but the USP of the brand and its products should be focused more because that helped them in differentiating from the competitors.

The decrease in the sales of handicraft goods was experienced during the industrial revolution with machine-made products which increased the competition for the hand made goods. The competition for a handicraft brand with the rest of the handicraft brands is also increasing so the entrepreneurs need to focus on the USP of the products and the brand to create value in the market.

\section{Conclusion}

Indian handicraft sector is one of the foremost important sectors for our heritage and culture and also in generating the highest employment potential and Forex earnings. But the lack of organization in this sector has led to the extinction of most of the crafts and led to the loss of livelihood of several artisans and craftsmen. The lack of marketing and entrepreneurial skills and analyses of market potential is also considered to be one of the major problems. This research will help in gaining knowledge on the sources available to analyze market potential, improvise marketing and help see opportunities of sustainable livelihood and give the entrepreneurs the technique of establishing a good relationship with the artisans.

\section{References}

[1] P. K. Jena, "Globalization of Indian handicrafts: A human development approach," Orissa review, vol. 65, pp. 19-25, 2008.

[2] Competitive study on Handicrafts sector in China;Ernst and Young 2012.

[3] S. Jadhav, "Indian handicrafts: Growing or depleting," IOSR Journal of Business and Management, vol. 2, no. 15, pp. 7-13, 2013.

[4] P.Majumdar and S. Banerjee, "Challenges to the sustainable growth of the micro-scale Kuhila Craft industry of India," in International Conference on Research into Design. Springer, 2017, pp. 267276.

[5] M. Dey, "Managerial Challenges of Handicraft Industry: An Indian Perspective," International Journal of Sciences: Basic and Applied Research, pp. 195-200, 2018.

[6] H. Kapur and S. Mittar, "Design intervention \& craft revival," International Journal of scientific and research publications, vol. 4, no. 10, pp. 1-5, 2014.

[7] S. Brown, "Can global craft and artisanship be the future of luxury fashion," Product Lifetimes And The Environment, vol. 27, 2015.

[8] J. Narzary, "Marketing problems and prospects of handloom and handicrafts industry in BTAD," Global Research Methodology Journal, vol. 2, no. 7, 2013.

[9] S. K. Hashmi, "Market for Indian handicrafts," Excel Journal of Engineering Technology and Management Science, vol. 1, no. 1, pp. 1-7, 2012. 
[10] W. A. Khan and Z. Amir, "Study of handicraft marketing strategies of artisans in Uttar Pradesh and its implications," Research Journal of Management Sciences, vol. 2, no. 2, pp. 23-26, 2013.

[11] V. A. Khan and Z. Amir, "Study of handicraft marketing strategies of artisans in Uttar Pradesh and its implications," Research Journal of Management Sciences, vol. 2, no. 2, pp. 23-26, 2013.

[12] I. Ghosal and B. Prasad, "Inspiring Digitalization of Handicraft Market: An empirical approach," Parikalpana: KIIT Journal of Management, vol. 15, no. 1and2, pp. 199-209, 2019.

[13] D. Silver, G. Kundu, and P, 2013 Handicraft products: Identify the factors that affect the buying decision of customers.

[14] S. Chetty, The case study method for research in small and medium-sized firms. International small business journal, 15(1)pp. 73-85, 1996.

[15] R. Fidel, "The case study method: a case study," Library and Information Science Research, vol. 6, no. 3, pp. 273-288, 1984.

[16] A. D. Massis and J. Kotlar, "The case study method in family business research: Guidelines for a qualitative scholarship," Journal of Family Business Strategy, vol. 5, no. 1, pp. 15-29, 2014.

[17] B. Dicicco-Bloom and B. F. Crabtree, "The qualitative research interview," Medical education, vol. 40, no. 4, pp. 314-321, 2006.

[18] B.L. Leech, "Asking questions: Techniques for semistructured inter- views," PS: Political science and politics, vol. 35, no. 4, pp. 665-668, 2002.

[19] S. Baškarada, "Qualitative Case Study Guidelines," The Qualitative Report, vol. 19, no. 40, pp. 118,2014 